\title{
Socio-Cognitive Factors Associated With Condom Use, Multiple Sexual Partnerships, and Contraception Use Among Sexually-Active Adolescent Girls in Uganda
}

\author{
Judith Nalukwago ${ }^{1,2,3}$, Rik Crutzen ${ }^{1}$, Bart van den Borne ${ }^{1}$, Paul M. Bukuluki ${ }^{3}$, Leonard Bufumbo ${ }^{2}$, Holly M. \\ Burke $^{2}$, Samuel Field ${ }^{2}$, Amos Zikusooka ${ }^{2}$, Anne A. Fiedler ${ }^{4} \&$ Jane Alaii $^{5}$ \\ ${ }^{1}$ Department of Health Promotion, CAPHRI Care and Public Health Research Institute, Faculty of Health, \\ Medicine and Life Science, Maastricht University, The Netherlands \\ ${ }^{2}$ FHI 360 (Family Health International), USAID/Communication for Healthy Communities Project, Uganda and \\ USA \\ ${ }^{3}$ Department of Social Work and Social Administration, School of Social Sciences, Makerere University, Uganda \\ ${ }^{4}$ Maternal and Child Health program, Jhpiego, Liberia \\ ${ }^{5}$ Context Factor Solutions, P.O Box 27598-00100, Nairobi, Kenya
}

Correspondence: Judith Nalukwago, Department of Health Promotion, Maastricht University, The Netherlands. Tel: 31-68-396-3732. E-mail: j.nalukwago@maastrichtuniversity.nl

Received: May 16, 2018 Accepted: June 20, 2018 Online Published: July 11, 2018

doi:10.5539/gjhs.v10n8p41 URL: https://doi.org/10.5539/gjhs.v10n8p41

\begin{abstract}
Many adolescent girls start sexual activity early which exposes them to health risks of HIV and unplanned pregnancies. However, adolescent girls are less likely than boys to initiate discussion or demand use of condoms. Multiple sexual partnerships among girls are reported to be on the rise with eminent transactional sex and pre-marital relationships. The unmet need for contraception among adolescent girls is also high. A cross-sectional survey covering 16 districts in Uganda assessed the socio-cognitive factors associated with condom use, multiple sexual partnerships and contraception use among sexually active adolescent girls $(\mathrm{N}=255)$. There were strong associations between feeling confident to discuss contraceptive methods with a partner $(\mathrm{OR}=9.41,95 \% \mathrm{CI}=3.54$, 25.06), being comfortable to use contraception $(\mathrm{OR}=30.61,95 \% \mathrm{CI}=4.10,228.64)$, discussing contraception use with someone $(\mathrm{OR}=10.53,95 \% \mathrm{CI}=5.61,19.78)$, and contraception use. Whereas knowledge was found to have no significant relationship with service uptake, information services remain important in clearing any misconceptions and addressing any health concerns. It is imperative to explore communication factors including skills development and providing adequate health information to guide dialogue among adolescents and their key influencers.
\end{abstract}

Keywords: Adolescent girls, condom use, contraception use, multiple sexual partnerships

\section{Abbreviations}

SRH: Sexual and Reproductive Health

TPB: Theory of Planned Behavior

SSA: sub-Saharan Africa

PPS: Probability Proportional to Size

\section{Introduction}

Adolescent girls in Uganda face high risks of HIV/AIDS and unplanned pregnancies. The country recorded a 3.0\% HIV prevalence among adolescent girls aged 15-19 and a teenage pregnancy rate that slightly increased from $24 \%$ in 2011 to $25 \%$ in 2016 (MOH, 2012; UBOS, 2018). The sexual and reproductive health (SRH) needs of these adolescents are inadequately addressed within the existing services system (Birungi et al., 2008; MOH, 2010). The scantiness of gender and age disaggregated program data for this target group increases the difficulty to develop targeted SRH programs (UNICEF, 2016). Understanding the socio-cognitive factors associated with adolescent sexual behaviors allows for better design of behavioral change programs targeted at adolescents. Many adolescent 
girls start sexual activity early, and this exposes them to health risks (Hardee, Gay, Croce-Galis, \& Afari-Dwamena, 2014; Neema, Musisi, \& Kibombo, 2004; UBOS, 2012; MOH, 2004). Health risks such as sexually transmitted infections (STIs) and maternal deaths associated with unsafe deliveries are aggravated by early marriages and limited access to basic needs (Bantebya, Muhanguzi, \& Watson, 2014; Cortez, Saadat, Marinda, \& Odutolu, 2016; Loaiza \& Liang, 2013). As such, girls are challenged with limited opportunities and choices to negotiate, make health decisions, and demand access to quality SRH services (Klugman et al., 2014; Singh \& Darroch, 2012; UNICEF, 2015; Williamson, 2014).

Designing adolescent sexual and reproductive health programs to address the risks requires understanding of adolescent sexual behaviors such as condom use, multiple sexual partnerships, and contraception use. Although a key motivator to use condoms among adolescents is the heightened concern for pregnancy prevention over HIV/STIs, girls are less likely than boys to initiate discussion or demand use of condoms (Cortez et al., 2016; Widdice, Cornell, Liang, \& Halpern-Felsher, 2006). The decision to use condoms is often controlled by a woman's partner (Baxter \& Abdool Karim, 2016). Multiple sexual partnerships among adolescent girls are also reported to be on the rise where transactional sex, girls engaging in pre-marital relationships with older men, arranged marriages for financial gain, sexual coercion and forced sex are eminent (Bantebya et al., 2014; Amin et al., 2013; Doyle, Mavedzenge, Plummer, \& Ross, 2012; Kazaura \& Masatu, 2009). In Uganda, adolescent girls aged 15-19 who reported having multiple sexual partners in the past 12 months increased from $2.1 \%$ in 2011 to $2.7 \%$ in 2016 [UBOS, 2018; UBOS, 2012]. Further, there is an unmet need for contraception among adolescent girls (Obare et al., 2011). Contraceptive use among married and sexually active unmarried adolescents aged $15-19$ shows a 30\% unmet need for family planning [UBOS, 2018]. Studies show persistent challenges in obtaining and using contraceptives. The challenges include; inadequate knowledge, social stigma, cost, perceived side effects, provider bias, and limited health facilities that provide adolescent SRH services (MOH, 2010; Ankomah, Anyanti, Adebayo, \& Giwa, 2013; Jonas, Crutzen, van den Borne, \& Reddy, 2017; Singh \& Darroch, 2014; Villarruel, Jemmott III, Jemmott, \& Ronis, 2004).

Although previous studies have examined the prevalence and trends in HIV knowledge and sexual behavior, little is known about the socio-cognitive factors of sexual behaviors among sexually active adolescent girls in Uganda. There is less focus on understanding sexual behavioral patterns of adolescent girls aged 15-19 as a distinct group from the often-generalized youth or young adults. Therefore, distinctively assessing the factors associated with condom use, multiple sexual partnerships and contraceptive use among sexually active adolescent girls is critical, and the focus of this study. This is vital for contextualizing implementation of adolescent SRH interventions using relevant theoretical frameworks that are linked to behavioral models. This study concerns secondary data analysis of a cross-sectional survey. Although the aim of the survey was not to test a specific theory, the items used in the analysis for this paper are linked to constructs based on the Theory of Planned Behavior.

\section{Methods}

A cross-sectional survey was conducted in 2015. The survey covered 16 districts (Lira, Amuru, Ntungamo, Ibanda, Mbale, Kumi, Iganga, Buyende, Arua, Nebbi, Moroto, Kaabong, Mukono, Sembabule, Kasese, Kyenjojo) spread across the eight regions of Uganda. The districts were purposively selected considering; the availability of United States Government (USG) supported health services, high prevalence of specified health issue like HIV/AIDS and teenage pregnancy; and contextual comparisons of rural and urban characteristics. The survey collected data from men and women aged 15-49, but for the present study only data from sexually active adolescent girls aged 15-19 were included.

\subsection{Study Participants and Sampling}

The study used a stratified multi-stage probability sampling design where sampling occurred in four stages. Eighty parishes were randomly selected from the 16 districts using stratified, probability proportional to size (PPS) systematic sampling. For each sampled parish, a list of villages in the parish was obtained and 3 villages randomly sampled using PPS systematic sampling. Ten households were sampled from each randomly selected village. Household samples were drawn with uniform probability using a sampling frame/list generated with the local leaders. A member list for each sampled household was generated. Basic demographic information about each household member was collected and used for selection of eligible individual participants using a Kish selection grid. The latter is a method for selecting members within a household to be interviewed (Kish, 1949; CHC, 2016). For this study, selected data for 255 sexually active adolescent girls aged 15-19 was used. The sexually active adolescent girls were selected based on adolescent girls that reported the age when they had sexual intercourse for the very first time. 


\subsection{Measures}

Socio-demographic and sexual behaviors measures. The study assessed the following socio-demographics: age, education level, occupation, begun childbearing, marital status, and sexual debut. The scale categories of these variables are listed in Table 1. All three sexual behaviors (condom use, multiple sexual partnerships, and contraception use) were assessed with one item (actual behavior) and dichotomized (yes/ no and 0-1/ 2 or more).

Socio-cognitive factors. The socio-cognitive factors that were assessed differed per outcome. Based on the Theory of Planned Behavior, the socio-cognitive factors were categorized as perceived behavioral control/ self-efficacy, attitude, subjective norm, and behavioral intention. Other factors such as psychological barrier and knowledge were included. Tables 2-4 show the operationalization at item level (including scale categories) for all factors regarding condom use, multiple sexual partnership, and contraception use respectively.

\subsection{Ethical Approval}

Ethical approval for the study was obtained from the United States of America federally registered institutional review board of FHI 360 (Family Health International), the Protection of Human Subjects Committee, under reference 616862-1, and in Uganda by the Government accredited Makerere School of Public Health Research Ethics Committee, under reference 259. Consent to conduct the study was obtained from Uganda National Council for Science and Technology and Office of the President. The study team requested and obtained waiver of written consent to increase confidentiality because signed informed consent forms would be the only link to the participants' identity in this study. Adolescent consenting procedures were undertaken in two ways: verbal informed consent was obtained from emancipated adolescent 15-17 years (either married or not living under the care of a parent/guardian); and verbal informed parental/guardian consent and adolescent assent were obtained from non-emancipated adolescents 15-17 years (minors living under the care of a parent/guardian). For adolescents aged 18-19, verbal informed consent was sought from each participant before any study specific activities were undertaken. The consenting process was conducted in a local language that the potential participant understood. Participants were given time to ask questions for clarity. Per ethical approval, verbal informed consent was obtained for each participant and documented via signature of the study staff member who obtained consent.

\subsection{Data Analysis}

\subsubsection{The Theory of Planned Behavior}

The study used the theory of planned behavior (TPB) to guide analysis and interpretation of the data. TPB has been globally used to examine adolescent sexual behavior, mainly condom use (Buhi \& Goodson, 2007; Heeren, Jemmott III, Mandeya, \& Tyler, 2007; McEachan, Conner, Taylor, \& Lawton, 2011; Fishbein \& Ajzen, 2010). The TPB postulates that intention is the main determinant of behavior, and it is influenced by attitude, subjective norm, and perceived behavioral control (self-efficacy) (Fishbein \& Ajzen, 2010; Glanz, Rimer, \& Viswanath. 2008; Cooke \& French, 2008). This study uses the socio-cognitive factors of behavioral intention, attitude, subjective norm, and perceived behavioral control/ self-efficacy to assess associations with actual sexual behavior. The study also includes other factors such as knowledge and psychological barriers that have been widely used and studied in sub-Saharan Africa (SSA) as predictors of behavior (Obare et al., 2011; Bakibinga et al., 2016; Eggers et al., 2016; Krugu, Mevissen, Debpuur, \& Ruiter, 2016). The outcome measure are the actual sexual behaviors (condom use, multiple sexual partnerships, and contraception use) among sexually active adolescent girls.

\subsubsection{Sample Weights}

Before analysis, sample weights were calculated based on parish, village, household and household member. The weights were determined based on probabilities that: parish is selected; village is selected conditional to parish being selected; household is selected conditional to village being selected; and household member is selected conditional to household being selected. Those probabilities were multiplied, and then the inverse was taken as the individual sampling weights (CHC, 2016). The weight domain variable was created, set as 1 if the person was included in the analysis, and 0 if not. In these analyses, the highest-level sampling unit, the parish, was specified as the primary sampling unit. Adding sampling weights helped to ensure that individuals were sampled with equal probabilities (Winship \& Radbill, 1994). It also helped to reduce the bias created by an imperfect sampling frame, non-response and coverage errors resulting from under or over representation of certain groups (Antal \& Rothenbühler, 2015; Verma \& Lê, 1996; Kalton \& Kasprzyk, 1986). Using weighted data for estimation of regression models gives covariance and variance estimates that are unbiased and consistent estimates of quantities in the population (Kish, 1949).

Descriptive statistics were run, and data were analyzed using logistic regression procedure. 


\subsubsection{Descriptive Frequencies}

Descriptive frequencies were run to understand the characteristics of the data. For analysis, descriptive frequencies were run for socio-demographic characteristics including; age, education level, occupation, whether girls had a child, marital status, and sexual debut.

\subsubsection{Logistic Regression Analysis}

Binary logistic regression model was used to analyze socio-cognitive factors associated with condom use, multiple sexual partnerships, and contraception use. Logistic regression analyses were used because all outcome variables were dichotomous (Tabachnick \& Fidell, 2013; Field, 2009). The factors in the regression model were categorized as: independent (socio-cognitive and marital status) and outcome (sexual behavior) variables. The independent variables were all categorical variables, where the first scale option was used as reference category.

\section{Results}

\subsection{Socio-Demographics}

A total of 255 sexually active adolescent girls were included in the analysis. The majority were 18 years (31\%, $\mathrm{n}=80)$ or 19 years $(32 \%, \mathrm{n}=82)$ old. Sixty-nine percent $(\mathrm{n}=169)$ of the respondents had attained primary level education. Thirty-five percent $(n=88)$ reported having a child and $32 \%(n=79)$ reported that they were married (Table 1).

Table 1. Socio-demographic characteristics of respondents ( $\mathrm{N}=255)$

\begin{tabular}{llll}
\hline Measures & Scale categories & Number (frequency) & Percentage (\%) \\
\hline & 15 & 13 & 5 \\
Age of respondents in years & 16 & 29 & 11 \\
& 17 & 51 & 20 \\
& 18 & 80 & 31 \\
& 19 & 82 & 32 \\
\hline \multirow{5}{*}{ Education level } & Primary & 169 & 69 \\
& Secondary (“O” level) & 70 & 29 \\
& Tertiary & 3 & 1 \\
\hline \multirow{5}{*}{ Occupation of respondents } & Subsistence farmers & 43 & 17 \\
& Commercial farmers & 79 & 31 \\
& Fishery-related jobs & 5 & 2 \\
& Laborer/ domestic worker & 30 & 12 \\
& Petty trader/ Hawker & 14 & 6 \\
& Owns business with 3 or more employees & 8 & 3 \\
& Uniformed services & 4 & 2 \\
& Students & 61 & 24 \\
\hline Begun childbearing & Yes & 88 & 35 \\
& No & 166 & 65 \\
\hline \multirow{2}{*}{ Marital status } & Married & 79 & 32 \\
\hline & Unmarried & 172 & 68 \\
\hline
\end{tabular}

\subsubsection{Sexual Debut Among Adolescent Girls}

Almost everybody $(98 \%, \mathrm{n}=250)$ mentioned age when they had sexual intercourse for the very first time, indicating that they were sexually active (the remaining $2 \%$ were excluded from further analyses). Of these, $19 \%$ $(\mathrm{n}=47)$ reported their age at first sex was 14 years, $25 \%(\mathrm{n}=62)$ at 15 years, $21 \%(\mathrm{n}=53)$ at 16 years, $17 \%(\mathrm{n}=43)$ at 17 years, and $10 \%(\mathrm{n}=25)$ at 18 years. The median age at first sex for the adolescent girls was 15 years. 


\subsection{Factors Associated With Condom Use Among Adolescent Girls}

Regarding actual condom use, $41 \%(\mathrm{n}=104)$ of the adolescent girls reported having used a condom at last sexual intercourse. Table 2 summarizes the association between socio-cognitive factors and marital status with condom use. The results indicate that there were no significant associations with condom use.

Table 2. Factors associated with condom use

\begin{tabular}{|c|c|c|c|c|}
\hline \multirow{2}{*}{ Measures } & \multirow{2}{*}{ Scale categories } & \multirow{2}{*}{ Frequency } & \multicolumn{2}{|l|}{ Bivariate } \\
\hline & & & OR $(95 \% \mathrm{CI})$ & $P$ \\
\hline \multicolumn{5}{|l|}{$\begin{array}{l}\text { Perceived behavioral control/self-efficacy on } \\
\text { condom use }\end{array}$} \\
\hline \multirow{4}{*}{$\begin{array}{l}\text { Easy to suggest to partner that we use a } \\
\text { condom }\end{array}$} & Strongly disagree & 35 & Ref & \\
\hline & Disagree & 43 & $1.041(0.422,2.565)$ & 0.931 \\
\hline & Agree & 90 & $0.731(0.330,1.619)$ & 0.441 \\
\hline & Strongly Agree & 64 & $0.852(0.369,1.968)$ & 0.708 \\
\hline \multirow{3}{*}{$\begin{array}{l}\text { Comfortable talking with a sexual partner } \\
\text { about condoms }\end{array}$} & Not very comfortable & 71 & Ref & \\
\hline & $\begin{array}{l}\text { Somewhat } \\
\text { comfortable }\end{array}$ & 58 & $1.008(0.500,2.033)$ & 0.982 \\
\hline & Very comfortable & 113 & $0.628(0.341,1.157)$ & 0.136 \\
\hline \multicolumn{5}{|l|}{ Attitude } \\
\hline \multirow{4}{*}{$\begin{array}{l}\text { The use of condoms can make sex more } \\
\text { stimulating }\end{array}$} & Strongly disagree & 46 & Ref & \\
\hline & Disagree & 82 & $0.575(0.276,1.197)$ & 0.139 \\
\hline & Agree & 61 & $0.582(0.266,1.276)$ & 0.177 \\
\hline & Strongly Agree & 13 & $1.150(0.335,3.946)$ & 0.824 \\
\hline \multirow{4}{*}{ Condoms are unreliable } & Strongly disagree & 35 & Ref & \\
\hline & Disagree & 78 & $0.662(0.297,1.477)$ & 0.314 \\
\hline & Agree & 83 & $0.433(0.193,0.974)$ & 0.041 \\
\hline & Strongly Agree & 33 & $0.700(0.271,1.807)$ & 0.461 \\
\hline \multicolumn{5}{|l|}{ Subjective norm } \\
\hline \multirow{2}{*}{$\begin{array}{l}\text { Discussed condom use with anyone in the last } \\
\text { six months }\end{array}$} & No & 181 & Ref & \\
\hline & Yes & 72 & $0.538(0.301,0.963)$ & 0.037 \\
\hline \multicolumn{5}{|l|}{ Psychological barrier } \\
\hline \multirow{4}{*}{$\begin{array}{l}\text { It would be embarrassing to be seen buying } \\
\text { condoms in a store }\end{array}$} & Strongly disagree & 41 & Ref & \\
\hline & Disagree & 66 & $0.858(0.388,0.963)$ & 0.707 \\
\hline & Agree & 75 & $0.912(0.421,1.978)$ & 0.816 \\
\hline & Strongly Agree & 65 & $0.842(0.381,1.862)$ & 0.671 \\
\hline \multicolumn{5}{|l|}{ Knowledge on condoms } \\
\hline \multirow{2}{*}{ Condoms can protect someone from HIV } & Strongly Disagree & 9 & Ref & \\
\hline & Strongly Agree & 239 & $0.920(0.232,3.641)$ & 0.905 \\
\hline \multirow{2}{*}{$\begin{array}{l}\text { Condoms are an effective method of preventing } \\
\text { the spread of HIV/AIDS and other STDs }\end{array}$} & Strongly Disagree & 17 & Ref & \\
\hline & Strongly Agree & 225 & $0.985(0.363,2.672)$ & 0.977 \\
\hline \multicolumn{5}{|l|}{ Behavioral intention } \\
\hline \multirow{4}{*}{$\begin{array}{l}\text { Likely to use a condom during sex in the next } \\
\text { six months }\end{array}$} & Very Unlikely & 70 & Ref & \\
\hline & Unlikely & 51 & $0.992(0.477,2.060)$ & 0.982 \\
\hline & Likely & 67 & $0.605(0.299,1.223)$ & 0.161 \\
\hline & Very Likely & 47 & $1.027(0.485,2.171)$ & 0.945 \\
\hline
\end{tabular}




\begin{tabular}{lllll}
\hline $\begin{array}{l}\text { Likely to use a condom the next time one has } \\
\text { sexual intercourse }\end{array}$ & Very Unlikely & 63 & Ref \\
& Unlikely & 38 & $1.303(0.580,2.927)$ & 0.522 \\
& Likely & 86 & $0.719(0.367,1.410)$ & 0.337 \\
& Very Likely & 55 & $0.815(0.386,1.718)$ & 0.591 \\
\hline Marital status & Not Married & 174 & Ref & \\
Current marital status & Married & 80 & $1.572(0.918,2.692)$ & 0.099 \\
\end{tabular}

Note. $\mathrm{CI}=$ confidence; $\mathrm{OR}=$ Odds Ratios; $P=\mathrm{P}$-value.

\subsection{Factors associated with multiple sexual partnerships among adolescent girls}

In this study, $14 \%(n=35)$ of the adolescent girls reported having two or more partners. Table 3 summarizes the association between socio-cognitive factors and marital status with having multiple partners. The results indicate that there were no significant associations between socio-cognitive factors and having multiple partners. There was a strong negative association between being married and having multiple partners.

Table 3. Factors associated with multiple sexual partners

\begin{tabular}{|c|c|c|c|c|}
\hline \multirow{2}{*}{ Measures } & \multirow{2}{*}{ Scale categories } & \multirow{2}{*}{ Frequency } & \multicolumn{2}{|l|}{ Bivariate } \\
\hline & & & OR $(95 \% \mathrm{CI})$ & $P$ \\
\hline \multicolumn{5}{|l|}{$\begin{array}{l}\text { Perceived behavioral control/self-efficacy to } \\
\text { have one sexual partner }\end{array}$} \\
\hline \multirow{3}{*}{$\begin{array}{l}\text { Confident to have only one sexual partner in } \\
\text { the next six months }\end{array}$} & Not at all confident & 23 & Ref & \\
\hline & Moderately confident & 44 & $1.090(0.291,4.092)$ & 0.898 \\
\hline & Very confident & 179 & $0.568(0.175,1.850)$ & 0.348 \\
\hline \multicolumn{5}{|l|}{ Subjective norm } \\
\hline \multirow{2}{*}{$\begin{array}{l}\text { Discussed the risk of having multiple sexual } \\
\text { partners with someone in the last six months }\end{array}$} & No & 163 & Ref & \\
\hline & Yes & 86 & $0.994(0.469,2.106)$ & 0.987 \\
\hline
\end{tabular}

\section{Knowledge on the risk of having multiple sexual partners}

Reducing one's number of sexual partners can limit the spread of HIV

$\begin{array}{llll}\text { Disagree } & 5 & \text { Ref } & \\ \text { Agree } & 140 & 0.558(0.059,5.256) & 0.610 \\ \text { Strongly Agree } & 109 & 0.672(0.071,6.364) & 0.729\end{array}$

\begin{tabular}{lllll}
\hline Behavioral intention & Very Unlikely & 10 & Ref \\
& Unlikely & 18 & $0.524(0.029,9.469)$ & 0.662 \\
$\begin{array}{l}\text { Likely to have only one sexual partner in the } \\
\text { next six months }\end{array}$ & Likely & 77 & $1.553(0.178,13.583)$ & 0.691 \\
& Very Likely & 138 & $1.199(0.142,10.158)$ & 0.868 \\
\hline Marital status & Not Married & 217 & Ref & \\
Current marital status & Married & 35 & $0.052(0.007,0.390)$ & 0.004 \\
\hline
\end{tabular}

Note. $\mathrm{CI}=$ confidence; $\mathrm{OR}=\mathrm{Odds}$ Ratios; $P=\mathrm{P}$-value.

\subsection{Factors Associated With Contraception Use Among Adolescent Girls}

Regarding actual use of contraception, $31 \%(n=76)$ of the adolescent girls reported that they were using 
contraception with main partner to prevent pregnancy. Table 4 summarizes the association between socio-cognitive factors and marital status and using contraception. Specifically, feeling confident to discuss contraceptive methods with a partner and comfortable to use contraception were strongly associated with using it. Also, having discussed contraception use with someone was strongly associated with contraception use. Finally, the likelihood to use a contraceptive method was associated with actual contraception use. None of the other socio-cognitive factors, nor marital status were associated with contraception use.

Table 4. Factors associated with contraception use among adolescent girls

\begin{tabular}{|c|c|c|c|c|}
\hline \multirow{2}{*}{ Measures } & \multirow{2}{*}{ Scale categories } & \multirow{2}{*}{ Frequency } & \multicolumn{2}{|l|}{ Bivariate } \\
\hline & & & OR $(95 \% \mathrm{CI})$ & $P$ \\
\hline \multicolumn{5}{|l|}{$\begin{array}{l}\text { Perceived behavioral control/self-efficacy on } \\
\text { contraception use }\end{array}$} \\
\hline \multirow{3}{*}{$\begin{array}{l}\text { Comfortable discussing contraceptive methods } \\
\text { with your spouse/partner }\end{array}$} & Not very comfortable & 65 & Ref & \\
\hline & $\begin{array}{l}\text { Somewhat } \\
\text { comfortable }\end{array}$ & 42 & $5.485(1.777,16.930)$ & 0.003 \\
\hline & Very comfortable & 133 & $9.414(3.536,25.059)$ & 0.000 \\
\hline \multirow{3}{*}{$\begin{array}{l}\text { Confident to use a contraceptive method if one } \\
\text { wanted to }\end{array}$} & Not at all confident & 46 & Ref & \\
\hline & Moderately confident & 51 & $\begin{array}{l}20.158 \quad \quad(2.537 \\
160.165)\end{array}$ & 0.005 \\
\hline & Extremely confident & 147 & $\begin{array}{l}30.606 \quad(4.097 \\
228.640)\end{array}$ & 0.001 \\
\hline \multicolumn{5}{|l|}{ Attitude } \\
\hline \multirow{4}{*}{$\begin{array}{l}\text { Side effects from using contraception usually } \\
\text { disappear after a few months of contraception } \\
\text { use }\end{array}$} & Strongly disagree & 12 & Ref & \\
\hline & Disagree & 29 & $2.295(0.414,12.722)$ & 0.342 \\
\hline & Agree & 118 & $2.812(0.584,13.555)$ & 0.198 \\
\hline & Strongly Agree & 38 & $4.535(0.869,23.651)$ & 0.073 \\
\hline \multicolumn{5}{|l|}{ Subjective norm } \\
\hline \multirow{2}{*}{$\begin{array}{l}\text { Discussed contraception with someone in the } \\
\text { last six months }\end{array}$} & No & 155 & Ref & \\
\hline & Yes & 93 & $10.531(5.607,19.781)$ & 0.000 \\
\hline \multicolumn{5}{|l|}{ Knowledge on contraception } \\
\hline \multirow{3}{*}{$\begin{array}{l}\text { A woman and her child will be healthier if a } \\
\text { woman waits at least two years between } \\
\text { pregnancies }\end{array}$} & Disagree & 6 & Ref & \\
\hline & Agree & 140 & $2.352(0.265,20.887)$ & 0.443 \\
\hline & Strongly Agree & 102 & $2.093(0.233,18.821)$ & 0.510 \\
\hline \multirow{4}{*}{$\begin{array}{l}\text { Having too many children can be harmful to } \\
\text { the health and well-being of women and their } \\
\text { families }\end{array}$} & Strongly disagree & 3 & Ref & \\
\hline & Disagree & 11 & $0.194(0.008,4.670)$ & 0.312 \\
\hline & Agree & 119 & $0.704(0.060,8.230)$ & 0.779 \\
\hline & Strongly Agree & 114 & $1.112(0.095,12.953)$ & 0.933 \\
\hline \multirow{4}{*}{$\begin{array}{l}\text { It is easy for most women to get pregnant soon } \\
\text { after they stop using contraception }\end{array}$} & Strongly disagree & 5 & Ref & \\
\hline & Disagree & 17 & $0.899(0.072,11.171)$ & 0.934 \\
\hline & Agree & 124 & $2.269(0.247,20.836)$ & 0.469 \\
\hline & Strongly Agree & 64 & $2.760(0.293,26.019)$ & 0.375 \\
\hline
\end{tabular}




\begin{tabular}{|c|c|c|c|c|}
\hline \multirow{4}{*}{$\begin{array}{l}\text { Knowledge on the different types of } \\
\text { contraceptives to try }\end{array}$} & Strongly disagree & 4 & \multicolumn{2}{|l|}{ Ref } \\
\hline & Disagree & 1 & $0.000(0.000)$ & 1.000 \\
\hline & Agree & 141 & $1.560(0.157,15.467)$ & 0.704 \\
\hline & Strongly Agree & 82 & $1.282(0.126,12.999)$ & 0.833 \\
\hline \multicolumn{5}{|l|}{ Behavioral intention } \\
\hline \multirow{4}{*}{$\begin{array}{l}\text { Likely to use a contraceptive method in the next } \\
\text { six months }\end{array}$} & Very Unlikely & 71 & \multicolumn{2}{|l|}{ Ref } \\
\hline & Unlikely & 34 & \multicolumn{2}{|l|}{$0.636(0.065,6.189)$} \\
\hline & Likely & 59 & \multicolumn{2}{|c|}{$14.903(4.370,50.820) \quad 0.000$} \\
\hline & Very Likely & 74 & $\begin{array}{l}36.088 \quad(10.804, \\
120.540)\end{array}$ & 0.000 \\
\hline \multicolumn{5}{|l|}{ Marital status } \\
\hline \multirow{2}{*}{ Current marital status } & Not Married & 168 & Ref & \\
\hline & Married & 80 & $0.578(0.314,1.064)$ & 0.078 \\
\hline
\end{tabular}

Note. $\mathrm{CI}=$ confidence; $\mathrm{OR}=$ Odds Ratios; $P=\mathrm{P}$-value

\section{Discussion}

This study assessed social cognitive factors associated with sexual behaviors among sexually active adolescent girls in Uganda. Bivariate analyses showed that the socio-cognitive factors of perceived behavioral control/ self-efficacy, subjective norm, behavioral intention and marital status were strongly associated with using contraception. We found no significant association between socio-cognitive factors and marital status with condom use. Similarly, the results indicate no significant association between socio-cognitive factors and having multiple sexual partners. These findings are surprising, but this could (partly) result from the study not being designed from the outset to test TPB constructs and the relatively small sample size could have affected accuracy of estimating associations.

Nonetheless, some of the findings are comparable to other studies conducted in SSA. While many studies indicate high knowledge on condoms, little is known about consistent and correct use of condoms among teenage girls (UBOS, 2018; Amoran, 2012). This is evident in the study finding which showed no significant relationship between knowledge and use of condoms. Whereas knowledge was found to have no significant relationship with use of condoms, information services remain important in clearing any misconceptions and addressing any health concerns. Although several studies found that socio-cognitive factors such as perceived social norm, self-efficacy, attitudes, behavioral beliefs were significant predictors of intention to use condoms (Villarruel et al., 2004; Buhi \& Goodson, 2007; Rijsdijk et al., 2012), our study found that such socio-cognitive factors were not associated with actual use of condoms among sexually active adolescent girls. In concurrence with our findings, Catania et al., (1989) found that self-efficacy and subjective norms were non-significant predictors of condom use among adolescent girls. Similarly, Eggers et al., (2015) found that attitude, subjective norm, and self-efficacy were weakly correlated with condom use. The findings of this study seem to suggest the need to explore other socio-cognitive factors such as gender norms, having stable and long-term relationships, self-esteem, and cultural make-up that are associated with condom use among adolescents, as well as health communication factors to assess their effect on sexual behaviors. Gender norms that put men in a position of sexual dominance were found to limit women's ability to control their own reproductive and sexual health, as often seen in the belief that girls who carry or suggest using condoms are promiscuous (Pulerwitz, Michaelis, Verma, \& Weiss, 2010; Varga, 2003). Studies found widespread resistance to the use of condoms in stable and long-term relationships because of their association with lack of trust and illicit sex (Maharaj \& Cleland, 2005; Pulerwitz, Gortmaker, \& DeJong, 2000). A young man's self-esteem, his ability to speak openly to a girl, and his cultural make-up, were found to influence his readiness to use the condom (Centerwall \& Laack, 2008).

Regarding multiple sexual partnerships, it has been shown that adolescents often have multiple sequential partners because many of their relationships are short term (Georges, Thomas, \& Bignami Simona, 2014). Our study found a strong negative correlation between being married and having multiple sexual partners. This is consistent with Santelli, Brener, Lowry, Bhatt, \& Zabin, (1998) finding that married females were significantly less likely than their never-married counterparts to have had multiple partners in the past three months. A study by Catania et al., 
(1989) found that the increased number of sexual partners was associated with susceptibility beliefs to HIV, poorer sexual communication with partner, and greater peer acceptance for being sexually active. Our findings indicate that confidence to have only one sexual partner and discussing the risk of having multiple sexual partners with someone, were not significantly associated with multiple sexual partnerships among adolescent girls. Therefore, there is need to assess other factors found to be associated with multiple sexual partnerships such as susceptibility beliefs to HIV, gender power relations and beliefs found to indicate that young men often think that it is heroic to have many sexual partners, and girls engaging in transactional sex with older men who are seen as better able to provide for them economically (Catania et al., 1989; Centerwall \& Laack, 2008; Bantebya, Muhanguzi, \& Watson, 2014).

Contraceptive continuation over sustained periods of time is not assured for adolescents particularly because they tend to have more limited access than older individuals to family planning, more unpredictable and irregular sexual activity, and are less knowledgeable about how to use contraceptive methods effectively (Burger \& Inderbitzen, 1985). In concurrence with other studies (Blanc, Tsui, Croft, \& Trevitt, 2009), our survey found that knowledge on contraception is not significantly associated with its use. However, the unmet need for contraception, despite the desire to limit births or delay them for at least two years is high among unmarried adolescents in SSA - more than $40 \%$ in most countries (Bakibinga et al., 2016; Hindin \& Fatusi, 2009). Despite high sexual activity among adolescent girls in Uganda, contraceptive uptake is still low with only $43 \%$ sexually active unmarried adolescent girls, and 22\% married adolescent girls using a contraceptive method (UBOS, 2018). Our findings indicate that there is no significant association between marital status and contraception use. The low contraceptive uptake is linked to negative perceptions on contraceptive use among adolescents, partners and parents (Hardee et al., 2014; Kinaro, 2011; MacPhail, Pettifor, Pascoe, \& Rees, 2007; Murigi, Butto, Barasa, Maina, \& Munyalo, 2016). Studies in Ghana and Bangladesh on correlates of contraceptive use among female adolescents found that knowledge and contraception use had significant relationships (Khan, Hossain, \& Hoq, 2012; Nyarko, 2015), which contradicts our findings showing almost everyone agreeing to the knowledge statements, but not translated into use. However, Chandra-Mouli et al., (2017) found that knowledge gaps and misconceptions on contraception both reduce uptake and increase discontinuation of contraceptive use. Our study found that three socio-cognitive factors including perceived behavioral control/ self-efficacy, subjective norm, and behavioral intention were strongly associated with contraception use. This finding supports other studies that found contraceptive use to be associated with the ability to discuss sexual topics with sex partners and other influencers such as parents (Davies et al., 2006; Whitaker, Miller, May, \& Levin, 1999; Shrier, Goodman, \& Emans, 1999; Mbalinda, Kiwanuka, Eriksson, Wanyenze, \& Kaye, 2015). Although interventions that aim to increase contraceptive knowledge and availability to prevent unintended pregnancy would have little effect on their own (Chandra-Mouli et al., 2017), health promotion programs should strive to address broader aspects in adolescent health programming that include creating an enabling environment which is dully supported by theoretical models. To increase contraception use among adolescents, aspects such as gender inequalities, social norms, and understanding adolescent dynamics of married and unmarried adolescents ought to be explored and addressed (Chandra-Mouli et al., 2017).

\subsection{Limitations of the Study}

The study findings rely on self-report data which may have limitations of sexual activity recall bias and the potential for under-reporting of sexual behavior due to the sensitive nature of the subject (Mbalinda et al., 2015; Reid \& Aiken, 2011). Our focus on sexually active adolescent girls may limit generalization to the entire population. The relatively small sample size in the study provided results in very wide confidence intervals, which made it hard to demonstrate the association for some variables. The predictive measures of the study were approached theoretically using TPB, but the self-reported questionnaire was not structured as such. Therefore, given that the study was not designed to test TPB means that operationalizations are not in line with TPB guidelines (Ajzen, nd; Ajzen, 1991). For example, some measures - such as discussing contraception and condom use with others - might be indicative of subjective norm, but are not clearly in line with the conceptualization, nor the operationalization, as specified in the TPB (Ajzen, nd). The study was cross-sectional in nature where behavioral predictors were not studied over a long period of time to confirm the temporal assumptions. Therefore, longitudinal and experimental studies are required to confirm the assumptions (Sniehotta, 2009).

\section{Conclusion}

Health promotion programs in SSA are faced with the intricate challenge of designing practicable intervention approaches to address the reality that many adolescents are increasingly becoming sexually active by age 15 . Based on our findings that indicate strong associations between perceived behavioral control/ self-efficacy, subjective norm, and behavioral intention, it is important to improve contraception communication among 
adolescents and their key influencers. Specifically, health promotion programs should provide adequate information on SRH to guide dialogue among adolescents and their key influencers such as health workers, parents, partners, and peers (Jonas et al., 2016; Pilgrim et al., 2014; Aarø et al., 2014). Creating an enabling environment that addresses aspects such as gender inequalities, social norms, and understanding adolescent dynamics of married and unmarried adolescents is pertinent (Chandra-Mouli et al., 2017). In this regard, further research is needed to find out other factors such as gender differences associated with adolescent sexual behavior, and practicable approaches on strengthening communication skills for key influencers of adolescents such as-parents, health workers, and religious leaders-to promote open dialogue on sexuality and SRH services. It is also important to learn from the experience of piloted adolescent health programs that have implemented aspects of interpersonal communication with and service delivery to adolescents. This will help in generating lessons for addressing the persistent challenges outlined in this paper, and guide improvements in the new and follow-on adolescent health targeted interventions.

\section{Authors' Contributions}

$\mathrm{JN}$ led in conceptualization and writing of the manuscript, led data analysis, contributed to study design, and data collection; RC, BvdB and $\mathrm{PB}$, contributed to conceptualization of this study, data analysis, guided the structuring and technical writing of the manuscript; LB, HB, SF, AZ and AF contributed to study design, supported in data collection and cleaning, and reviewing of the manuscript for consistency. JA contributed to conceptualization of this study, data analysis, guided the structuring and technical writing of the manuscript. All authors reviewed and approved the final version of the manuscript.

\section{Acknowledgements}

The authors wishe to thank USAID Uganda for funding the research activities through FHI 360, and Family Health International (FHI 360) for approving the use of project (Communication for Healthy Communities) data for this study. The authors wish to thank Maastricht University for supporting and funding the present study technical writing and publication requirements. The authors thank Andrew Kabala, Justus Atwijukire and CHC regional teams for supporting the data collection exercise.

\section{Competing Interests Statement}

The authors declare that there are no competing or potential conflicts of interest.

\section{References}

Aarø, L. E., Mathews, C., Kaaya, S., Katahoire, A. R., Onya H., Abraham, C., \& De Vries, H. (2014). Promoting sexual and reproductive health among adolescents in southern and eastern Africa (PREPARE): project design and conceptual framework. BMC Public Health, 14(1), 54. https://doi.org/10.1186/1471-2458-14-54

Ajzen, I. (nd). Constructing Theory of Planned Behavior Questionnaire. Retrieved May 8, 2018, from https://people.umass.edu/aizen/pdf/tpb.measurement.pdf

Ajzen, I. (1991). The theory of planned behavior. Organizational Behavior and Human Decision Processes, 50(2), 179-211. https://doi.org/10.1016/0749-5978(91)90020-T

Amin, S., Austrian K., Chau M., Glazer K., Green E., Stewart D., Stoner M. (2013). The Adolescent Girls Vulnerability Index: Guiding strategic investment in Uganda.

Amoran, O. E. (2012). A comparative analysis of predictors of teenage pregnancy and its prevention in a rural town in Western Nigeria. International Journal for Equity in Health, 11(1), 1. https://doi.org/10.1186/1475-9276-11-37

Ankomah, A., Anyanti, J., Adebayo, S., \& Giwa, A. (2013). Barriers to Contraceptive Use among Married Young Adults in Nigeria: A Qualitative Study.

Antal, E., \& Rothenbühler, M. (2015). Weighting in the Swiss Household Panel Technical report. Retrieved November 15, 2017, from http://forscenter.ch/wp-content/uploads/2014/12/Weighting_technical_report.pdf

Bakibinga, P., Matanda, D. J., Ayiko, R., Rujumba, J., Muiruri, C., Amendah, D., \& Atela, M. (2016). Pregnancy history and current use of contraception among women of reproductive age in Burundi, Kenya, Rwanda, Tanzania and Uganda: analysis of demographic and health survey data. BMJ open, 6(3), https://doi.org/10.1136/bmjopen-2015-009991

Bantebya G. K., Muhanguzi F. K., \& Watson C. (2014). Adolescent girls in the balance: Changes and continuity in social norms and practices around marriage and education in Uganda. Retrieved February 25, 2017, from https://www.odi.org/sites/odi.org.uk/files/odi-assets/publications-opinion-files/9180.pdf 
Baxter C., \& Abdool Karim S. (2016). Combination HIV prevention options for young women in Africa. African Journal of AIDS Research, 15(2), 109-121. https://doi.org/10.2989/16085906.2016.1196224

Birungi, H., Mugisha, J. F., Nyombi, J., Obare, F., Evelia, H., \& Nyinkavu, H. (2008). Sexual and reproductive health needs of adolescents perinatally infected with HIV in Uganda. FRONTIERS Final Report.

Blanc, A. K., Tsui, A. O, Croft, T. N, \& Trevitt, J. L. (2009). Patterns and trends in adolescents' contraceptive use and discontinuation in developing countries and comparisons with adult women. International Perspectives on Sexual and Reproductive health, 63-71. https://doi.org/10.1363/3506309

Buhi, E. R., \& Goodson, P. (2007). Predictors of adolescent sexual behavior and intention: A theory-guided systematic review. Journal of Adolescent Health, 40(1), 4-21. https://doi.org/10.1016/j.jadohealth.2006.09.027

Burger, J. M., \& Inderbitzen, H. M. (1985). Predicting contraceptive behavior among college students: The role of communication, knowledge, sexual anxiety, and self-esteem. Archives of Sexual Behavior, 14(4), 343-350. https://doi.org/10.1007/BF01550849

Catania, J. A., Coates, T. J., Greenblatt, R. M., Dolcini, M. M., Kegeles, S. M., Puckett, S., ... \& Miller, J. (1989). Predictors of condom use and multiple partnered sex among sexually - active adolescent women: Implications for aids - related health interventions.

Centerwall, E., \& Laack, S., (2008). Young Men as Equal Partners. RFSU, Riksförbundet för sexuell upplysning, The Swedish Association for Sexuality Education, Stockholm.

Chandra-Mouli, V., Parameshwar, P. S., Parry, M., Lane, C., Hainsworth, G., Wong, S., ... \& Say, L. (2017). A never-before opportunity to strengthen investment and action on adolescent contraception, and what we must do to make full use of it. Reproductive health, 14(1), 85. https://doi.org/10.1186/s12978-017-0347-9

CHC-Communication for Healthy Communities. (2016). Evaluative survey of an Integrated Health Communication Campaign in Uganda-Observation 1 Report. USAID and FHI360. Kampala, Uganda.

Cooke, R., \& French, D. P. (2008). How well do the theory of reasoned action and theory of planned behaviour predict intentions and attendance at screening programmes? A meta-analysis. Psychology and Health, 23(7), 745-765. https://doi.org/10.1080/08870440701544437

Cortez, R., Saadat, S., Marinda, E., \& Odutolu, O. (2016). Adolescent Fertility and Sexual Health in Nigeria.

Davies, S. L., DiClemente, R. J., Wingood, G. M., Person, S. D., Dix, E. S., Harrington, K., ... \& Oh, K. (2006). Predictors of inconsistent contraceptive use among adolescent girls: findings from a prospective study. Journal of Adolescent Health, 39(1), 43-49. https://doi.org/10.1016/j.jadohealth.2005.10.011

Doyle, A. M., Mavedzenge, S. N., Plummer, M. L., \& Ross, D. A. (2012). The sexual behaviour of adolescents in sub - Saharan Africa: patterns and trends from national surveys. Tropical Medicine \& International Health, 17(7), 796-807. https://doi.org/10.1111/j.1365-3156.2012.03005.x

Eggers, S. M., Aarø, L. E., Bos, A. E., Mathews, C., Kaaya, S. F., Onya, H., \& de Vries, H. (2016). Socio-cognitive predictors of condom use and intentions among adolescents in three sub-saharan sites. Archives of Sexual Behavior, 45(2), 353-365. https://doi.org/10.1007/s10508-015-0525-1

Eggers, S. M., Taylor, M., Sathiparsad, R., Bos, A. E., \& de Vries, H. (2015). Predicting safe sex: Assessment of autoregressive and cross-lagged effects within the Theory of Planned Behavior. Journal of Health Psychology, 20(11), 1397-1404. https://doi.org/10.1177/1359105313512354

Field, A. (2009). Discovering Statistics Using SPSS (3rd ed.). SAGE Publications Ltd. London.

Fishbein, M., \& Ajzen, I. (2010). Predicting and Changing Behavior. The Reasoned Action Approach. Psychology press. Taylor \& Francis Group. New York, USA.

Georges, G., Thomas, L. K., \& Bignami Simona, B. (2014). Sexual risk behavior: Factors associated with the number of sexual partners and consistent condom use among adolescents in four sub-Saharan African countries. Retrieved March 27, 2017, from http://paa2014.princeton.edu/papers/141169

Glanz, K., Rimer, B. K., \& Viswanath, K. (2008). Health Behavior and Health Education: Theory, Research, and Practice (4th ed.). John Wiley \& Sons, Inc. San Francisco, CA- USA,

Hardee, K., Gay, J., Croce-Galis, M., \& Afari-Dwamena, N. A. (2014). What HIV programs work for adolescent girls? Journal of Acquired Immune Deficiency Syndromes, 66, S176-S185. https://doi.org/10.1097/QAI.0000000000000182 
Heeren, G. A., Jemmott III, J. B., Mandeya, A., \& Tyler, J. C. (2007). Theory-Based Predictors of Condom Use among university Students in the United States and South Africa. AIDS Education \& Prevention, 19(1), 1-12. https://doi.org/10.1521/aeap.2007.19.1.1

Hindin, M. J., \& Fatusi, A. O. (2009). Adolescent sexual and reproductive health in developing countries: an overview of trends and interventions. International Perspectives on Sexual and Reproductive Health, 35(2), 58-62. https://doi.org/10.1363/3505809

Jonas, K., Crutzen, R., van den Borne, B., \& Reddy, P. (2017). Healthcare workers' behaviors and personal determinants associated with providing adequate sexual and reproductive healthcare services in sub-Saharan Africa: a systematic review. BMC Pregnancy and Childbirth, 17(1), 86. https://doi.org/10.1186/s12884-017-1268-x

Jonas, K., Reddy, P., van den Borne, B., Sewpaul, R., Nyembezi, A., Naidoo, P., \& Crutzen, R. (2016). Predictors of nurses' and midwives' intentions to provide maternal and child healthcare services to adolescents in South Africa. BMC Health Services Research, 16(1), 658. https://doi.org/10.1186/s12913-016-1901-9

Kalton, G., \& Kasprzyk, D. (1986). The treatment of missing survey data. Survey methodology, 12(1), 1-16.

Kazaura, M. R., \& Masatu, M. C. (2009). Sexual practices among unmarried adolescents in Tanzania. BMC Public Health, 9(1), 373. https://doi.org/10.1186/1471-2458-9-373

Khan, M. M., Hossain, M. E., \& Hoq, M. N. (2012). Determinants of contraception use among female adolescents in Bangladesh. Asian Social Science, 8(12), 181.

Kinaro, J. W. (2011). Perceptions as a barrier to Contraceptive Use Among Adolescents: A case Study of Nairobi, Kenya (Unpublished master's thesis). Population Studies and Research Institute (PSRI), University of Nairobi, Kenya.

Kish, L. (1949). A procedure for objective respondent selection within the household. Journal of the American Statistical Association, 44(247), 380-387. https://doi.org/10.1080/01621459.1949.10483314

Klugman, J., Hanmer, L., Twigg, S., Hasan, T., McCleary-Sills, J., \& Santamaria, J. (2014). Voice and agency: Empowering women and girls for shared prosperity: World Bank Publications. https://doi.org/10.1596/978-1-4648-0359-8

Krugu, J. K., Mevissen, F. E. F., Debpuur, C., \& Ruiter, R. A. C. (2016). Psychosocial correlates of condom use intentions among junior high school students in Bolgatanga Municipality of Ghana. International Journal of Sexual Health, 28, 96-110. https://doi.org/10.1080/19317611.2015.1124162

Loaiza, E., \& Liang, M. (2013). Adolescent pregnancy: a review of the evidence. UNFPA, New York, USA.

MacPhail, C., Pettifor, A. E., Pascoe, S., \& Rees, H. V. (2007). Contraception use and pregnancy among 15-24 year-old South African women: a nationally representative cross-sectional survey. BMC medicine, 5(1), 31. https://doi.org/10.1186/1741-7015-5-31

Maharaj, P., \& Cleland, J. (2005). Risk perception and condom use among married or cohabiting couples in KwaZulu-Natal, South Africa. International Family Planning Perspectives, 24-29. https://doi.org/10.1363/3102405

Mbalinda, S. N., Kiwanuka, N., Eriksson, L. E., Wanyenze, R. K., \& Kaye, D. K. (2015). Correlates of ever had sex among perinatally HIV-infected adolescents in Uganda. Reproductive Health, 12(1), 96. https://doi.org/10.1186/s12978-015-0082-z

McEachan, R. R. C., Conner, M., Taylor, N. J., \& Lawton, R. J. (2011). Prospective prediction of health-related behaviours with the theory of planned behaviour: A meta-analysis. Health Psychology Review, 5(2), 97-144. https://doi.org/10.1080/17437199.2010.521684

Ministry of Health- MOH. (2004). National Adolescent Health Policy For Uganda. Ministry of Health Reproductive Health Division. Kampala- Uganda. Retrieved December 30, 2016, from www.youth-policy.com/Policies/UGAyouthpol2004.pdf

Ministry of Health- MOH. (2010). Health Sector Strategic Plan III 2010/11-2014/15. Government of Uganda Kampala, Uganda.

Ministry of Health- MOH. (2012). Uganda AIDS Indicator Survey 2011. Ministry of Health. Kampala, Uganda.

Murigi, M., Butto, D., Barasa, S., Maina, E., \& Munyalo, B. (2016). Overcoming Barriers to Contraceptive Uptake among Adolescents: The Case of Kiambu County, Kenya. Journal of Biosciences and Medicines, 4(09), 1. 
https://doi.org/10.4236/jbm.2016.49001

Neema, S., Musisi, N., \& Kibombo, R. (2004). Adolescent sexual and reproductive health in Uganda: a synthesis of research evidence (Vol. 14). Alan Guttmacher Institute.

Nyarko, S. H. (2015). Prevalence and correlates of contraceptive use among female adolescents in Ghana. BMC Women's Health, 15(1), 60. https://doi.org/10.1186/s12905-015-0221-2

Obare, F., Birungi, H., Undie, C. C., Wanjiru, M., Liambila, W., \& Askew, I. (2011). Levels trends and determinants of contraceptive use among adolescent girls in Kenya. APHIA II Operations Research Project/ Population Council.

Pilgrim, N. A., Ahmed, S., Gray, R. H., Sekasanvu, J., Lutalo, T., Nalugoda, F., \& Wawer, M. J. (2014). Family structure effects on early sexual debut among adolescent girls in Rakai, Uganda. Vulnerable Children and Youth Studies, 9(3), 193-205. https://doi.org/10.1080/17450128.2013.842027

Pulerwitz, J., Gortmaker, S. L., \& DeJong, W. (2000). Measuring sexual relationship power in HIV/STD research. Sex Roles, 42(7), 637-660. https://doi.org/10.1023/A:1007051506972

Pulerwitz, J., Michaelis, A., Verma, R., \& Weiss, E. (2010). Addressing gender dynamics and engaging men in HIV programs: lessons learned from Horizons research. Public Health Reports, 125(2), 282-292. https://doi.org/10.1177/003335491012500219

Reid, A. E., \& Aiken, L. S. (2011). Integration of five health behaviour models: common strengths and unique contributions to understanding condom use. Psychology \& Health, 26(11), 1499-1520. https://doi.org/10.1080/08870446.2011.572259

Rijsdijk, L. E., Bos, A. E., Lie, R., Ruiter, R. A., Leerlooijer, J. N., \& Kok, G. (2012). Correlates of delayed sexual intercourse and condom use among adolescents in Uganda: a cross-sectional study. BMC Public Health, 12(1), 817. https://doi.org/10.1186/1471-2458-12-817

Santelli, J. S., Brener, N. D., Lowry, R., Bhatt, A., \& Zabin, L. S. (1998). Multiple sexual partners among US adolescents and young adults. Family Planning Perspectives, 271-275. https://doi.org/10.2307/2991502

Shrier, L. A., Goodman, E., \& Emans, S. J. (1999). Partner condom use among adolescent girls with sexually transmitted diseases. Journal of Adolescent Health, 24(5), 357-361. https://doi.org/10.1016/S1054-139X(98)00133-5

Singh, S., \& Darroch, J. (2014). Adding it up. costs and benefits of contraceptive services. New York: Guttmacher Institute and United Nations Population Fund: UNFPA). Retrieved December 01, 2016, from http://www.guttmacher.org/pubs/AIU-2012-estimates.pdf

Singh, S., \& Darroch, J. E. (2012). Adding it up: Costs and benefits of contraceptive services. Guttmacher Institute and UNFPA.

Sniehotta, F. (2009). An experimental test of the theory of planned behavior. Applied Psychology: Health and Well - Being, 1(2), 257-270, https://doi.org/10.1111/j.1758-0854.2009.01013.x

Tabachnick, B. G., \& Fidell, S. L. (2013). Using Multivariate Statistics (6th ed.). Pearson Education, Inc. United States of America.

Uganda Bureau of Statistics (UBOS) and ICF International Inc. (2012). Uganda Demographic and Health Survey 2011. Kampala, Uganda: UBOS and Calverton, Maryland: ICF International Inc.

Uganda Bureau of Statistics (UBOS) and ICF. (2018). Uganda Demographic and Health Survey 2016. Kampala, Uganda and Rockville, Maryland, USA: UBOS and ICF.

UNICEF. (2015). The national strategy to end child marriage and teenage pregnancy 2014/2015 - 2019/2020: A society free from child marriage and teenage pregnancy. Republic of Uganda.

UNICEF. (2016). Collecting and Reporting of Sex- and Age-Disaggregated Data on Adolescents at the Sub-National Level. Data Abstraction Guide - November 2016.

Varga, C. A. (2003). How gender roles influence sexual and reproductive health among South African adolescents. Studies in Family Planning, 34(3), 160-172. https://doi.org/10.1111/j.1728-4465.2003.00160.x

Verma, V., \& Lê, T. (1996). An analysis of sampling errors for the demographic and health surveys. International Statistical Review/Revue Internationale de Statistique, 265-294. https://doi.org/10.2307/1403786

Villarruel, A. M., Jemmott III, J. B., Jemmott, L. S., \& Ronis, D. L. (2004). Predictors of sexual intercourse and 
condom use intentions among Spanish-dominant Latino youth: a test of the planned behavior theory. Nursing Research, 53(3), 172-181. https://doi.org/10.1097/00006199-200405000-00004

Whitaker, D. J., Miller, K. S., May, D. C., \& Levin, M. L. (1999). Teenage partners' communication about sexual risk and condom use: the importance of parent-teenager discussions. Family Planning Perspectives, 117-121. https://doi.org/10.2307/2991693

Widdice, L. E., Cornell, J. L., Liang, W., \& Halpern-Felsher, B. L. (2006). Having sex and condom use: Potential risks and benefits reported by young, sexually inexperienced adolescents. Journal of Adolescent Health, 39(4), 588-595. https://doi.org/10.1016/j.jadohealth.2006.03.016

Williamson, N. (2014). State of the World Population 2013. Motherhood in Childhood: Facing the Challenge of Adolescent Pregnancy. New York: United Nations Population Fund.

Winship, C., \& Radbill, L. (1994). Sampling weights and regression analysis. Sociological Methods \& Research, 23(2), 230-257. https://doi.org/10.1177/0049124194023002004

\section{Copyrights}

Copyright for this article is retained by the author(s), with first publication rights granted to the journal.

This is an open-access article distributed under the terms and conditions of the Creative Commons Attribution license (http://creativecommons.org/licenses/by/4.0/). 